\title{
Occurrence and antibiotic resistance of enterotoxigenic Staphylococcus aureus in raw ovine and caprine milk in Greece
}

\author{
Andreana Pexara ${ }^{1}$ - Nikolaos Solomakos ${ }^{1}$. \\ Daniel Sergelidis $^{2}$ - Apostolos S. Angelidis ${ }^{3}$. \\ Alexandros Govaris ${ }^{1}$
}

Received: 27 August 2015 /Revised: 27 October 2015 / Accepted: 19 November 2015 /

Published online: 1 December 2015

(C) INRA and Springer-Verlag France 2015

\begin{abstract}
Ovine $(n=140)$ and caprine $(n=35)$ raw bulk tank milk samples from farms in central Greece were examined for the occurrence of enterotoxigenic Staphylococcus aureus. The S. aureus isolates were screened for staphylococcal enterotoxin (SE) production, the presence of enterotoxin genes, antibiotic resistance (AR), and methicillin resistance. S. aureus was isolated from $24.3 \%$ and $31.4 \%$ of ovine and caprine milk samples, respectively. Among the $S$. aureus isolates of ovine milk $(n=34)$ and caprine $(n=11)$ milk, the enterotoxigenic (SEA-SED) isolates were $21(61.8 \%)$ and 7 $(63.6 \%)$ for the ovine and caprine milk, respectively. Most toxigenic isolates harbored more than one toxin gene and a total of 11 distinct toxinotypes were detected. The most frequent toxin-gene combinations were "sec, tst" (8 isolates), "seb, seg, sei, tst" (4), "seb, seg, sei" (3), and "seb" (3). Six isolates displayed multiple AR towards up to five antimicrobials. Among ovine milk isolates, the highest resistance frequency was observed towards erythromycin $(11.8 \%$ of the isolates) and tetracycline $(8.8 \%)$. Among caprine milk isolates, the most frequent resistance was observed towards erythromycin (18.2\%). One methicillin-resistant $S$. aureus (MRSA) isolate was detected in an ovine milk sample and belonged to spa type t4038. This spa type
\end{abstract}

Andreana Pexara

apexara@vet.uth.gr

1 Laboratory of Hygiene of Foods of Animal Origin, Faculty of Veterinary Medicine, University of Thessaly, 224 Trikalon Street, 43100 Karditsa, Greece

2 Laboratory of Hygiene of Foods of Animal Origin, Department of Hygiene and Technology of Foods of Animal Origin, Faculty of Veterinary Medicine, School of Health Sciences, Aristotle University of Thessaloniki, 54124 Thessaloniki, Greece

3 Laboratory of Milk Hygiene and Technology, Department of Food Hygiene and Technology, Faculty of Veterinary Medicine, School of Health Sciences, Aristotle University of Thessaloniki, 54124 Thessaloniki, Greece 
has been isolated for the first time in Greece and, to our knowledge, has not been previously reported among MRSA isolates from raw milk or dairy products worldwide.

Keywords Staphylococcus aureus $\cdot$ Enterotoxins · Antibiotic resistance $\cdot$ MRSA

\section{Introduction}

Staphylococcus aureus is a Gram-positive, opportunistic pathogen for both animals and humans resulting in a plethora of clinical manifestations, whereas from a food safety perspective, $S$. aureus is a frequent cause of bacterial food intoxication in humans. Staphylococcal food poisoning (SFP) is caused by the ingestion of food containing one or more preformed staphylococcal enterotoxins (SEs) produced by enterotoxigenic strains of staphylococci and, in particular, S. aureus. Many serologically distinct SEs or SE-like toxins have been identified, which include the classical SEs (SEA through SEE), newer SEs (SEG through SEJ), and more recent ones (SEK through SEX). All enterotoxins share superantigenic activity, whereas some (SEA-SEE, SER, SES, SET) have been proven to be emetic. Toxic shock syndrome toxin-1 (TSSA-1), initially designated as SEF, is considered the major cause of toxic shock syndrome, and lacks emetic activity. Another public health concern is the presence of antibiotic-resistant (AR) and, in particular, methicillin-resistant $S$. aureus (MRSA) strains in foodproducing animals and foods of animal origin (EFSA 2009).

$S$. aureus can be isolated from various environmental sites such as dust, water, air, and feces. A large percentage of the human population is a permanent or intermittent carrier of $S$. aureus. S. aureus is also present on the skin and mucosae of foodproducing animals, and it is a frequent etiological agent of intramammary infections in dairy animals, including small ruminants. Consequently, $S$. aureus can gain access to the raw milk supply either by direct excretion from udders with clinical or subclinical staphylococcal mastitis or via contamination from the environment during improper handling and processing of raw milk. Raw milk is a good substrate for $S$. aureus growth and, under permissive conditions, enterotoxin production as well (Pexara et al. 2012). Although pasteurization inactivates $S$. aureus cells, the SEs are resistant to heat and generally retain their biological activity even after pasteurization. As result, dairy products, including raw milk, have frequently been implicated in SFP (De Buyser et al. 2001).

$S$. aureus appears to be isolated at high frequencies from raw small ruminants' milk, and studies conducted in various countries have shown that $S$. aureus isolates from caprine milk $(\mathrm{CM})$ and ovine milk $(\mathrm{OM})$ frequently produce SEs or harbor genes encoding for their synthesis (Jørgensen et al. 2005; Morandi et al. 2007). In addition, AR and MRSA $S$. aureus strains have been isolated from both bovine and small ruminants' milk in various countries, as summarized in the review of Pexara et al. (2013). To our knowledge, no such data are available from Greece.

The objectives of this study were to estimate the prevalence of $S$. aureus in raw, bulk tank OM and CM produced in farms of central Greece and to examine the isolated strains in terms of (a) enteroxigenicity, (b) antimicrobial susceptibility, (c) the presence of encoding SE genes, and (d) the presence of MRSA encoding genes. 


\section{Material and methods}

\subsection{Sample collection}

Samples from $136 \mathrm{OM}$ and $35 \mathrm{CM}$ farm bulk tanks (200-250 L milk) and 4 OM collection center (250-300 L milk) in the region of Thessaly, central Greece, were collected between February and May 2014. Milk was sampled from farms using hand milking. Sampling of milk was performed according to the International Dairy Federation guidelines (ISO 2008). Milk samples (100 mL each) were placed in sterile glass containers and transported to the laboratory at $c a .4{ }^{\circ} \mathrm{C}$ within $6-12 \mathrm{~h}$ after sampling.

\subsection{Isolation of $S$. aureus}

Isolation of coagulase-positive staphylococci (CPS) was performed according to ISO 6888-1 (ISO 1999) on Baird-Parker agar supplemented with egg yolk tellurite emulsion (Oxoid, UK). Confirmation of the isolates to the species level was based upon Gram staining, catalase reaction, hemolysis test on Columbia agar with defibrinated sheep blood (Oxoid, UK), and biochemical characterization (API ID 32 Staph, bioMérieux, France). One $S$. aureus isolate from each positive milk sample was selected for further characterization. All isolates were stored at $-70{ }^{\circ} \mathrm{C}$ in Brain Heart Infusion broth (BHIB, Merck, Germany) with 25\% glycerol.

\subsection{Detection of enterotoxigenic $S$. aureus strains}

The $S$. aureus isolates were tested for the production of classical staphylococcal enterotoxins using a commercial enzyme immunoassay kit Ridascreen, SET-total (RBiopharm, Germany). Before testing, isolates were grown aerobically in BHIB for $24 \mathrm{~h}$ at $37{ }^{\circ} \mathrm{C}$. Fully grown cultures were filtered through $0.2-\mu \mathrm{m}$ membranes (Whatman FP30/0.2 CA-S, UK), and the filtrates were analyzed according to the manufacturer's instructions without quantification. The kit has a detection limit ca. $0.25 \mathrm{ng} \cdot \mathrm{mL}^{-1}$. Isolates found positive for SE production were tested using a different commercial enzyme immunoassay kit Ridascreen, SET-A,B,C,D,E (R-Biopharm, Germany) in order to determine the type of enterotoxin produced (A B, C, D, and E). The detection limit for this kit is in the range of $0.2-0.7 \mathrm{ng} \cdot \mathrm{mL}^{-1}$.

\subsection{Detection of staphylococcal enterotoxin genes (se) and of the toxic shock syndrome toxin-1 gene (tst)}

The $S$. aureus strains found to be enterotoxigenic based on the Ridascreen SET-total kit results were further examined for the presence of the se and tst genes by PCR using previously published primer sequences for sea (Tsen and Chen 1992), seb-see plus tst (Johnson et al. 1991), seg-sei (Jarraud et al. 1999), and sej genes (Monday and Bohach 1999). DNA extraction was conducted using a QIAamp DA minikit (Qiagen, Germany) according to the manufacturer's instructions. DNA amplification was performed in a Perkin-Elemer GeneAmp 2400 thermocycler (Applied Biosystems, UK). The reaction and amplification conditions used for the PCR assays were those described by Akineden et al. (2008). 
Positive controls used were S. aureus ATCC 19095 FRI 137 (sec, seh, seg, sei), ATCC 700699 (sea, sec, seg, sei, sel), ATCC 23235 (sed, seg, sei, sej), ATCC 14458 (seb), and ATCC 27664 (see).

\subsection{Determination of antibiotic resistance}

The antibiotic susceptibility of the $S$. aureus isolates to 13 antibiotics/antibiotic combinations was determined by the disk diffusion method according to the Clinical Laboratory Standards Institute guidelines (CLSI 2013) on Mueller-Hinton agar (Merck, Germany) plates. The antibiotics and the respective quantities (in $\mu \mathrm{g}$ ) per impregnated disk (BBL, Becton Dickinson, USA) were as follows: tetracycline (TE, $30)$, amikacin $(\mathrm{AK}, 30)$, gentamicin $(\mathrm{GM}, 10)$, cephalothin $(\mathrm{CF}, 30)$, tobramycin $(\mathrm{NN}$, 30), fusidic acid (FA, 10), amoxicillin+clavulanic acid (AMC, 20+10), ciprofloxacin (CIP, 5), sulfamethoxazole/trimethoprim (SXT, 23.75+1.25), ampicillin (AM, 10), cefoxitin (FOX, 30), clindamycin (DA, 2), and erythromycin (E, 15).

\subsection{Detection of mecA gene and spa typing}

DNA extraction from staphylococcal cells was performed according to Casey et al. (2006), and the detection of the mecA gene was carried out by PCR according to Murakami et al. (1991). A MRSA isolate from a previous study, spa type t127, was used as a positive control.

The amplification and sequencing of the spa gene was performed using a method based on DNA sequence typing of the $S$. aureus protein A gene (spa typing) which is currently considered a reliable single method for identifying the MRSA lineage (Airesde-Sousa et al. 2006). Typing was performed through the publicly available Ridom Spa Server (www.spaserver.ridom.de) (Harmsen et al. 2003).

\subsection{Statistical analysis}

The $95 \%$ confidence intervals (CI) for the estimated proportions of $S$. aureus-positive $\mathrm{OM}$ and $\mathrm{CM}$ samples were calculated using the exact probability method of Minitab (version 14, Minitab Inc., State College, PA, USA). The estimated proportions and their respective CIs were multiplied by 100 to yield percentage values.

\section{Results}

\subsection{Occurrence of enterotoxigenic $S$. aureus in ovine and caprine milk}

$S$. aureus was isolated from 34 out of the $140(24.3 \%)(95 \% \mathrm{CI}=17.4-32.2 \%)$ samples of OM and from 11 out of the $35(31.4 \%)(95 \% \mathrm{CI}=16.9-49.3 \%)$ samples of CM. One isolate per positive sample was further characterized, and the number of enterotoxigenic $S$. aureus isolates along with the SEs produced is listed in Table 1 .

Thirteen out of the $34(38.2 \%)$ OM isolates were negative for enterotoxin production whereas the remaining 21 isolates $(61.8 \%)$ were able to produce one of the "classical" SEs. SEB and SEC were the enterotoxin types most frequently detected, produced by 
Table 1 Production of enterotoxins (SEA-SEE) in S. aureus isolates from raw ovine (OM) and caprine milk (CM)

\begin{tabular}{lllllllll}
\hline \multirow{2}{*}{$\begin{array}{l}\text { Sample } \\
\text { origin }\end{array}$} & $\begin{array}{l}\text { No of } \\
\text { isolates }\end{array}$ & \multicolumn{6}{l}{ Enterotoxin types and number $(\%)$ of isolates producing the respective toxin } \\
\cline { 3 - 8 } & & SEA & SEB & SEC & SED & SEE & SEA, SEC & Total enterotoxigenic (\%) \\
\hline $\mathrm{OM}$ & 34 & $2(9.5)$ & $10(47.6)$ & $8(38.1)$ & $1(4.8)$ & - & - & $21(61.8)$ \\
$\mathrm{CM}$ & 11 & $1(14.3)$ & - & $5(71.4)$ & - & - & $1(14.3)$ & $7(63.6)$ \\
\hline
\end{tabular}

10 and $8 \mathrm{~S}$. aureus isolates, respectively, whereas none of the isolates were able to produce SEE.

For CM, seven out of the $11(63.6 \%)$ tested isolates were found to be enterotoxigenic (Table 1) and SEC was the enterotoxin type most frequently detected. None of the CM S. aureus isolates could produce SEB, SED, or SEE.

\subsection{Detection of $s e$ and $t$ st genes}

The toxin-gene profiles of enterotoxigenic $S$. aureus isolates are shown in Table 2. In $\mathrm{CM}$ isolates, the detection of se genes via PCR (sea, sec, and sea $+\mathrm{sec}$ ) paralleled the isolates' enterotoxin production phenotype that was determined by the application of immunoassays. In contrast, in six of the OM isolates, no correspondence was observed between the presence of enterotoxin genes and their enterotoxigenic phenotype. Thus, only the seg gene was detected (via PCR) in one SEA-positive isolate (isolate O1) while only the $s e b$, seg, and sei genes were detected in two SEC-positive (O19 and $\mathrm{O} 20)$ and one SED-positive isolate (O21). It is important to note that one SEC-positive isolate $(\mathrm{O} 18)$ yielded negative PCR results for all se genes tested, while the sec gene was detected in two SEC-negative isolates (O3 and O4).

Among all tested isolates, the genes most frequently detected were $t s t(53.6 \%)$, seg $(50 \%)$, and $s e b$, sei, and sec (46.4\%). None of the isolates harbored see. In OM isolates, the genes most frequently detected (61.9\%) were seb and seg. In CM isolates, sec was the gene most commonly detected $(71.4 \%)$ whereas seb was not detected in any of the tested isolates.

Five of the enterotoxigenic isolates (17.9\%) possessed only a single enterotoxin gene (sea, seb or seg). Eight isolates (28.6\%) carried the sec-tst gene combination, and seven $(25 \%)$ were positive for three genes (as shown in Table 2). Genotypes encoding four (seb, seg, sei, and tst or seb, seg, seh, and sei) and five (seb, sec, seg, sei, and tst) toxins were detected in five $(17.9 \%)$ and two $(7.1 \%)$ strains, respectively. The gene combinations most frequently detected (alone or in addition to other toxin genes) in toxin-gene-positive isolates were the seg-sei (detected in $12 \mathrm{OM}$ isolates and one CM isolate) and the tst-sec (detected in six OM and five CM isolates).

\subsection{Antibiotic susceptibility of $S$. aureus isolates}

None of the 45 tested $S$. aureus isolates showed resistance to CF, FA, AMC, or SXT (Table 3). For the remaining of the antimicrobials tested, the resistance 
Table 2 Toxin-gene profiles of enterotoxigenic $S$. aureus isolates from raw ovine and caprine milk

\begin{tabular}{|c|c|c|}
\hline Isolate & Gene & $\begin{array}{l}\text { Enterotoxin production } \\
\text { phenotype }^{\mathrm{a}}\end{array}$ \\
\hline $\mathrm{O} 1$ & seg & A \\
\hline $\mathrm{O} 2$ & sea, seg, sei & A \\
\hline $\mathrm{O} 3$ & seb, sec, seg, sei, tst & B \\
\hline $\mathrm{O} 4$ & seb, sec, seg, sei, tst & B \\
\hline O5 & $s e b$, seg, sei, tst & $\mathrm{B}$ \\
\hline O6 & seb, seg, sei, tst & B \\
\hline $\mathrm{O} 7$ & seb, seg, sei, tst & B \\
\hline O8 & $s e b, s e g, s e i, t s t$ & B \\
\hline O9 & $s e b$ & B \\
\hline $\mathrm{O} 10$ & $s e b$ & $\mathrm{~B}$ \\
\hline O11 & $s e b$ & B \\
\hline $\mathrm{O} 12$ & seb, seg, seh, sei & B \\
\hline $\mathrm{O} 13$ & sec, tst & $\mathrm{C}$ \\
\hline $\mathrm{O} 14$ & $\sec$, tst & $\mathrm{C}$ \\
\hline O15 & $\sec , t s t$ & $\mathrm{C}$ \\
\hline O16 & $\sec$, tst & $\mathrm{C}$ \\
\hline $\mathrm{O} 17$ & sec, seg, sei & $\mathrm{C}$ \\
\hline O18 & - & $\mathrm{C}$ \\
\hline O19 & seb, seg, sei & $\mathrm{C}$ \\
\hline $\mathrm{O} 20$ & seb, seg, sei & $\mathrm{C}$ \\
\hline $\mathrm{O} 21$ & seb, seg, sei & $\mathrm{D}$ \\
\hline $\mathrm{C} 1$ & sea & A \\
\hline $\mathrm{C} 2$ & sea, sec, tst & $\mathrm{A}, \mathrm{C}$ \\
\hline $\mathrm{C} 3$ & $\sec$, tst & $\mathrm{C}$ \\
\hline $\mathrm{C} 4$ & $\sec$, tst & $\mathrm{C}$ \\
\hline $\mathrm{C} 5$ & $\sec$, tst & $\mathrm{C}$ \\
\hline C6 & $\sec$, tst & $\mathrm{C}$ \\
\hline $\mathrm{C} 7$ & sec, seg, sei & $\mathrm{C}$ \\
\hline
\end{tabular}

$O$ ovine milk isolate, $C$ caprine milk isolate

${ }^{a}$ Enterotoxin-production phenotype as determined by the application of immunoassays

profiles of AR isolates were quite variable both in terms of the antimicrobial number and the type. For instance, whereas three isolates were found to be resistant to only a single antimicrobial (TE, E, or CIP), six isolates displayed multiple AR (to up to five antimicrobials, i.e., AK, NN, FOX, DA, and E in isolate O18). Overall, the highest resistance frequencies were observed for $\mathrm{E}$ $(11.8 \%)$ and $\mathrm{TE}(8.8 \%)$ in $\mathrm{OM}$ isolates and for $\mathrm{E}(18.2 \%)$ in $\mathrm{CM}$ isolates. Interestingly, O18, the only isolate which displayed resistance to FOX, was found to carry the mecA gene (MRSA). The spa typing of this isolate revealed type t4038. The MRSA isolate was able to synthesize SEC, but no sec gene was detected. 
Table 3 Antibiotic resistance profiles of S. aureus isolated from raw ovine $(\mathrm{OM})$ and caprine milk $(\mathrm{CM})$

\begin{tabular}{lll}
\hline Isolate origin & Resistance profile & $\begin{array}{l}\text { No. of resistant isolates } \\
\text { (isolate ID) }\end{array}$ \\
\hline OM $(n=34)$ & AK, NN, FOX, DA, E & $1(\mathrm{O} 18)^{*}$ \\
& NN, DA, CIP, E & $1(\mathrm{O} 3)$ \\
& AK, CIP, E & $1(\mathrm{O} 12)$ \\
& TE, E & $1(\mathrm{O} 9)$ \\
& AM, TE & $2(\mathrm{O} 19, \mathrm{O} 16)$ \\
& TE & $1(\mathrm{O} 21)$ \\
$\mathrm{CM}(n=11)$ & $\mathrm{GM}, \mathrm{E}$ & $1(\mathrm{C} 4)$ \\
& $\mathrm{E}$ & $1(\mathrm{C} 5)$ \\
& $\mathrm{CIP}$ & $1(\mathrm{C} 2)$ \\
\hline
\end{tabular}

$T E$ tetracycline, $A K$ amikacin, $G M$ gentamicin, $C F$ caphalothin, $N N$ tobramycin, $F A$ fusidic acid, $A M C$ amoxicillin/clavulanic acid, $C I P$ ciprofloxacin, $S X T$ sulphamethoxazole/trimethoprim, $A M$ ampicillin, $F O X$ cefoxitin, $D A$ clindamycin, $E$ erythromycin

*mecA-positive (MRSA) strain

\section{Discussion}

\subsection{Prevalence of $S$. aureus in ovine and caprine milk}

S. aureus was isolated from $24.3 \%$ of the OM samples and from $31.4 \%$ of the CM samples. Similar to our results, S. aureus was detected in $24 \%$ of the raw OM samples collected from Epirus, Greece (Fotou et al. 2011), whereas all milk samples collected from 21 sheep farms from the regions of Xanthi and Evros were positive for S. aureus (Alexopoulos et al. 2011).

The data regarding the prevalence of $S$. aureus in $\mathrm{CM}$ and OM from other countries are also quite variable (Mørk et al. 2003; Jørgensen et al. 2005; de Garnica et al. 2013; Spanu et al. 2013; Cortimiglia et al. 2015). Although differences in the sensitivity and specificity of the protocols used for bacterial isolation may have contributed to these variant results, the different husbandry practices applied in different countries may at least partly account for the aforementioned differences in prevalence estimates. Difficulties in managing the sanitary quality of $\mathrm{CM}$ and $\mathrm{OM}$ arise from a number of factors, including the low level of milk yield per animal, the milking process (frequently hand milking), the difficulties involved in machine milking, and the conditions under which herds or flocks are raised (Alexopoulos et al. 2011; Fotou et al. 2011).

\subsection{Detection of enterotoxigenic $S$. aureus}

A high abundance of SE-positive strains was observed among the S. aureus isolates in our study. These results are in accordance with literature data, particularly for CM, suggesting that goats are an important reservoir of enterotoxigenic staphylococci (Valle et al. 1990). Hence, SE production (SEA-SED) was demonstrated in $57.3-64 \%$ of the S. aureus isolates from Norwegian bulk CM (Jørgensen et al. 2005; Mørk et al. 2003). Forty five and $35 \%$ of the $S$. aureus isolates from bulk CM were characterized by 
enterotoxin production in Italy (Spanu et al. 2013) and Northern Ireland (Harvey and Gilmour 1988), respectively. However, other investigators reported a lower percentage of enterotoxigenic isolates (Foschino et al. 2002).

Among the types of SE produced by enterotoxigenic CM isolates, a high prevalence of SEC $(85.7 \%)$ was observed, which is consistent with previous studies (Foschino et al. 2002; Harvey and Gilmour 1988; Morandi et al. 2007; Scherrer et al. 2004; Valle et al. 1990). High proportions (85.2-94\%) of SEC production in SE-positive S. aureus isolates from bulk CM have also been reported in the studies of Jørgensen et al. (2005) and Spanu et al. (2013).

In our study, among the total enterotoxigenic OM isolates, a high percentage of SEC producers was observed (38.1\%); however, the enterotoxin type detected at the highest frequency was SEB (47.6\%). It should be noted, however, that since only one isolate per $S$. aureus-positive bulk tank milk sample was further characterized in our study, it is quite likely that more than one $S$. aureus genotype could have been present in the respective $S$. aureus-positive bulk tank milk samples. According to literature data, SEC appears to be the predominant toxin type detected in $S$. aureus isolated from OM and particularly from mastitic OM (Orden et al. 1992). It has been proposed that considerable geographical variation exists in the distribution of enterotoxigenic $S$. aureus (Jørgensen et al. 2005). The characterization of a greater number of OM isolates from different regions in Europe is necessary to determine the extent of the heterogeneity of $S$. aureus in terms of SE production.

In our study, with the exception of one $\mathrm{CM}$ isolate (C2) that was found capable of producing two enterotoxins (SEA and SEC) (Table 2), all SE-producing isolates produced only a single enterotoxin. Nonetheless, the ability of $S$. aureus strains to produce more than one SE has been reported and the combination of SEA- and SECproducing strains was shown to be the most common among CM isolates producing two enterotoxins (Jørgensen et al. 2005; Valle et al. 1990). The low production frequency of other enterotoxins (especially SED) and the lack of SEE synthesis for both OM and CM isolates are in agreement with previous studies (Harvey and Gilmour 1988; Normanno et al. 2007a; Valle et al. 1990).

Published studies have attributed outbreaks of SFP after consumption of small ruminants' raw milk and raw milk products to the production of SEA, SEB, and SEC (De Buyser et al. 2001; Schønberg and Wåltorp 2001). Hence, in the present study, the $S$. aureus isolates found capable of producing any of these SE can pose public health risks. In particular, the high percentage of SEC-positive $S$. aureus isolates among other enterotoxigenic types (from both OM and CM) is of great importance because SEC has been recognized as an important cause of SFP associated with the consumption of dairy products (Manfreda et al. 2005).

\subsection{Detection of se and tst genes}

For all SE-positive OM isolates, the PCR assay results confirmed the presence of the corresponding se gene. However, this was not the case for five out of the 21 SEpositive CM isolates. Differences between the results obtained via PCR and those obtained via the application of immunoassays have been also reported previously (Cremonesi et al. 2007; Jørgensen et al. 2005; Morandi et al. 2007; Poli et al. 2007). In our study, the observation that the corresponding genes were not detected by PCR in 
one SEA-positive and in three SEC-positive isolates by enzyme immunoassay (all from OM) is in agreement with previous studies. Morandi et al. (2007) proposed that the lack of detection of the corresponding genes in three SEA- and SEC-positive OM isolates could indicate the existence of sequence variations in se genes or the production of an unknown toxin that cross reacts during the immunological detection of SEA and SEC. Isolates testing positive for SEA by reversed passive latex agglutination but negative for sea by PCR have also been observed in animals other than sheep (Jørgensen et al. 2005).

On the contrary, the sec gene was detected in two SEC-negative OM isolates in our study. Similarly, Poli et al. (2007) and Cremonesi et al. (2007) did not detect SEC by SET-RPLA in the sec-positive isolates from cheeses made with raw bovine and CM, respectively. This finding may be explained by the lower sensitivity of the immunoassay methods used or by the fact that the detection of se genes does not necessarily indicate toxin production and biological activity (Morandi et al. 2007).

In agreement with previous studies, we found that enterotoxigenic $\mathrm{CM}$ isolates mainly harbored the sec gene (Akineden et al. 2008; Lyra et al. 2013; Scherrer et al. 2004). None of our CM isolates carried the seb gene. Similarly, several studies reported that none of the strains isolated from bovine and CM and dairy products harbored the seb gene (Akineden et al. 2001; Lyra et al. 2013). In other studies, however, the seb gene was detected in $S$. aureus isolates from milk and dairy products at various frequencies (Jørgensen et al. 2005; Zouharova and Rysanek 2008). The fact that seb was the most commonly detected SE genotype in isolates from OM in our study is in agreement with the findings of previous studies (Arcuri et al. 2010; Peles et al. 2007).

None of the strains in our study harbored the see gene, in agreement with other investigations on $S$. aureus isolates from milk and dairy products (Arcuri et al. 2010; Carfora et al. 2015; Cremonesi et al. 2007; Jørgensen et al. 2005; Poli et al. 2007; Zouharova and Rysanek 2008).

In the present work, half of the enterotoxigenic isolates carried two or more (up to four) se genes (Table 2). The presence of two or more se genes in S. aureus strains from milk and dairy products was also reported in other studies (Carfora et al. 2015; Cremonesi et al. 2007; Morandi et al. 2007; Poli et al. 2007).

The frequent combination of seg and sei genes in toxigenic S. aureus strains in our study is consistent with previous reports (Lyra et al. 2013; Rosec and Gigaud 2002; Scherrer et al. 2004). Some authors reported a predominant and systematic co-detection of seg and sei genes (Rosec and Gigaud 2002) whereas others have reported their presence individually or in different combinations with other se genes (Arcuri et al. 2010; Cremonesi et al. 2007; Zouharova and Rysanek 2008). The association between seg and sei has been attributed to their location within the same gene cluster $(e g c)$ in the genomic island mSA $b$ (also known as SaPIn3/m3) (Malachowa and DeLeo 2010). In our study, one isolate harboring only the seg gene was found. The occurrence of strains harboring only seg or sei may be explained by mispriming due to a point mutation in one of these genes or the existence of variants in the egc cluster, combinations of toxingene-containing mobile elements such as plasmids and genomic islands in the same strain, or even a new type of genetic mobile element (Arcuri et al. 2010).

The co-detection of sec and tst genes observed in our study is consistent with other studies of $S$. aureus from mammary secretions of dairy animals and from bulk milk (Akineden et al. 2008; Jørgensen et al. 2005; Orden et al. 1992; Scherrer et al. 2004).

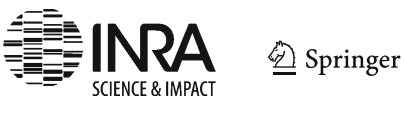


In our study, a high occurrence of "new" SE genes (especially seg and sei) was observed in isolates found positive for the production of classical SEs. Since, to date, no commercial tests for the "new" types of SEs exist, S. aureus isolates containing the corresponding genes should be considered as potential SE producers. A review of the literature seems to indicate an increase in the number of potentially enterotoxigenic $S$. aureus isolates from milk and dairy products carrying "new" SE genes in addition to the classical ones (Arcuri et al. 2010; Rosec and Gigaud 2002; Zouharova and Rysanek 2008). It should be noted, however, that in our study the prevalence of se genes may have been underestimated because only the isolates testing positive for SE production via immunoassays were tested with PCR, as well as due to the fact that the isolates were not tested for the presence of the recently described se genes (sek-ser and seu). Although Commission Regulation (EC) No 1441/2007 (EC 2007) specifies the term "staphylococcal enterotoxins" as those compounds which are detectable by commercial immunoassays (toxins SEA-SEE), further investigations are needed to evaluate the ability of $S$. aureus isolates to produce "new" SEs in milk and evaluate their role in food safety.

\subsection{Antibiotic susceptibility of $S$. aureus isolates}

The results of the present study revealed that the highest resistance frequency was observed towards E (11.8\%) and TE (8.8\%) among OM isolates and towards E (18.2\%) among CM $S$. aureus isolates. When testing the antibiotic susceptibility of $S$. aureus isolates from OM and CM, Vyletělova et al. (2011) reported that $20 \%$ and $30 \%$ of the $\mathrm{OM}$ and CM isolates, respectively, was found resistance to E. Rola et al. (2015) reported that $6.3 \%$ of CPS isolated from raw CM was resistant to TE and FOX. TE and $\mathrm{E}$ are commonly used antibiotics in animals for the treatment of infections. The long-term usage of these antibiotics is considered to be the greatest risk for the selection of resistant strains.

The present study showed that three $S$. aureus isolates (6.7\%) were resistant to three or more antimicrobial agents. Rola et al. (2015) reported that only $2.9 \%$ of CPS isolated from raw $\mathrm{CM}$ was resistant to three or more antimicrobial agents.

In our study, the MRSA isolate was resistant to AK, NN, FOX, DA, and E. Cortimiglia et al. (2015) reported that three out of four MRSA isolates from bulk $\mathrm{CM}$ were resistant to TE, besides being resistant to penicillin and FOX. In addition, two of them were resistant to trimethoprim and one to DA. The AR profile of their third MRSA isolate was different, displaying additional resistance to kanamycin, streptomycin, E, and DA.

The observation in our study that the MRSA isolate was able to produce SEs (SEC) is in accordance with previous studies. Normanno et al. (2007b) reported that all MRSA strains isolated from foods of animal origin in Italy were able to produce SEs. The most frequently detected enterotoxin was SED followed by SEA and SEC. MRSA frequently contain genes encoding for SE production (Fey et al. 2003). These findings provide further evidence that MRSA may also be involved in food poisoning outbreaks, as reported by Jones et al. (2002) and Kluytmans et al. (1995).

In our study, the detected MRSA spa type $\mathrm{t} 4038$ has been isolated for the first time in Greece and is not among the reported spa types from raw milk or dairy isolates (www.spaserver.ridom.de). According to Ridom Spa Server, the global frequency of 
occurrence of t4038 is low and has been reported in the Netherlands. More frequently, other MRSA spa types seem to be associated with raw milk, dairy products, and farm personnel such as t127 (Carfora et al. 2015; Cortimiglia et al. 2015), t899 (CC398) (Cortimiglia et al. 2015), t011 (CC398), t567, and t108 (Bardiau et al. 2013) and spa types t011, t034, and t2576 (Fessler et al. 2010). Despite the fact that the spa type detected in our study is not among those associated with increased virulence in humans, typing of MRSA isolates can provide useful data on the epidemiology and monitoring of MRSA in foods.

In conclusion, the presence of enterotoxigenic $S$. aureus and MRSA in CM and OM and their potential introduction into the dairy chain could pose public health risks. The implementation of Good Hygiene Practices and Pre-Harvest Food Safety Principles at the farm level, the prudent use of antibiotics in veterinary medicine, and the avoidance of raw milk consumption are of paramount importance in order to minimize public health risks.

Acknowledgments The research was supported by the Research Committee of University of Thessaly, Greece.

Compliance with ethical standards This article does not contain any studies with human or animal subjects performed by any of the authors.

Conflict of interest The authors declare that they have no competing interests.

\section{References}

Aires-de-Sousa M, Boye K, de Lencastre H, Deplano A, Enright MC, Etienne J, Friedrich A, Harmsen D, Holmes A, Huijsdens XW, Kearns AM, Mellmann A, Meugnier H, Rasheed JK, Spalburg E, Strommenger B, Struelens MJ, Tenover FC, Thomas J, Vogel U, Westh H, Xu J, Witte W (2006) High interlaboratory reproducibility of DNA sequence-based typing of bacteria in a multicenter study. J Clin Microbiol 44:619-621

Akineden Ö, Annemüller C, Hassan AA, Lämmler C, Wolter W, Zschöck M (2001) Toxin genes and other characteristics of Staphylococcus aureus isolates from milk of cows with mastitis. Clin Diagn Lab Immunol 8:959-964

Akineden Ö, Hassan AA, Schneider E, Usleber E (2008) Enterotoxigenic properties of Staphylococcus aureus isolated from goats' milk cheese. Int J Food Microbiol 124:211-216

Alexopoulos A, Tzatzimakis G, Bezirtzoglou E, Plessas S, Stavropoulou E, Sinapis E, Abas Z (2011) Microbiological quality and related factors of sheep milk produced in farms of NE Greece. Anaerobe 17:276-279

Arcuri EF, ngelo FF, Guimarães MFM, Talon R, de Fatima BM, Leroy S, Loiseau G, Lange CC, de Andrade NJ, Montet D (2010) Toxigenic status of Staphylococcus aureus isolated from bovine raw milk and Minas frescal cheese in Brazil. J Food Prot 73:2225-2231

Bardiau M, Yamazaki K, Duprez J-N, Taminiau B, Mainil JG, Ote I (2013) Genotypic and phenotypic characterization of methicillin-resistant Staphylococcus aureus (MRSA) isolated from milk of bovine mastitis. Lett Appl Microbiol 57:181-186

Carfora V, Caprioli A, Marri N, Sagrafoli D, Boselli C, Giacinti G, Giangolini G, Sorbara L, Dottarelli S, Battisti A, Amatiste S (2015) Enterotoxin genes, enterotoxin production, and methicillin resistance in Staphylococcus aureus isolated from milk and dairy products in Central Italy. Int Dairy J 42:12-15

Casey AL, Worthington T, Caddick JM, Hilton AC, Lamber PA, Elliot TSJ (2006) RAPD for the typing of coagulase-negative staphylococci implicated in catheter-related bloodstream infection. J Infect 52:282-289 
CLSI (2013) Performance standards for antimicrobial susceptibility testing; 23rd informational supplement, M100-S23. Clinical and Laboratory Standard Institute, Pennsylvania

Commission Regulation (EC) No. 1441 (2007) Amending Regulation (EC) No 2073/2005 on microbiological criteria for foodstuffs. OJ EL 322:12-29

Cortimiglia C, Bianchini V, Franco A, Caprioli A, Battisti A, Colombo L, Stradiotto K, Vezzoli F, Luini M (2015) Prevalence of Staphylococcus aureus and methicillin-resistant S. aureus in bulk tank milk from dairy goat farms in Northern Italy. J Dairy Sci 98:1-5

Cremonesi P, Perez G, Pisoni G, Moroni P, Morandi S, Luzzana M, Brasca M, Castiglioni B (2007) Detection of enterotoxigenic Staphylococcus aureus isolates in raw milk cheese. Lett Appl Microbiol 45:586-591

De Buyser M-L, Dufour B, Maire M, Lafarge V (2001) Implication of milk and milk products in food-borne diseases in France and in different industrialised countries. Int J Food Microbiol 67:1-17

de Garnica ML, Linage B, Carriedo JA, Santos JA, Gonzalo C (2013) Staphylococcus aureus and Escherichia coli prevalence in ovine bulk tank milk. Small Rumin Res 115:108-112

EFSA (2009) Scientific opinion of the panel on biological hazards on a request from the European Commission on assessment of the public health significance of methicillin resistant Staphylococcus aureus (MRSA) in animals and foods. EFSA J 993:1-73

Fessler A, Scott C, Kadlec K, Ehricht R, Monecke S, Schwarz S (2010) Characterization of methicillinresistant Staphylococcus aureus ST398 from cases of bovine mastitis. J Antimicrob Chemother 65:619625

Fey PD, Saïd-Salim B, Rupp ME, Hinrichs SH, Boxrud DJ, Davis CC, Kreiswirth BN, Schlievert PM (2003) Comparative molecular analysis of community- or hospital-acquired methicillin-resistant Staphylococcus aureus. Antimicrob Agents Chemother 47:196-203

Foschino R, Invernizzi A, Barucco R, Stradiotto K (2002) Microbial composition, including the incidence of pathogens, of goat milk from the Bergamo region of Italy during a lactation year. J Dairy Res 69:213-225

Fotou K, Tzora A, Voidarou C, Alexopoulos A, Plessas S, Avgeris I, Bezirtzoglou E, Akrida-Demertzi K, Demertzis PG (2011) Isolation of microbial pathogens of subclinical mastitis from raw sheep's milk of Epirus (Greece) and their role in its hygiene. Anaerobe 17:315-319

Harmsen D, Claus H, Witte W, Rothgänger J, Claus H, Turnwald D, Vogel U (2003) Typing of methicillinresistant Staphylococcus aureus in a university hospital setting by using novel software for spa repeat determination and database management. J Clin Microbiol 41:5442-5448

Harvey J, Gilmour A (1988) Isolation and characterization of staphylococci from goats milk produced in Northern Ireland. Lett Appl Microbiol 7:79-82

ISO (International Organization for Standardization) (1999) ISO 6888-1: microbiology of food and animal feeding stuffs-horizontal method for the enumeration of coagulase positive staphylococci (Staphylococcus aureus and other species). International Organization for Standardization, Geneva

ISO 707:2008 (IDF 50: 2008) (2008) Milk and milk products-guidance on sampling. International Organization for Standardization, Geneva

Jarraud S, Cozon G, Vandenesch F, Bes M, Etienne J, Lina G (1999) Involvement of enterotoxins G and I in staphylococcal toxic shock syndrome and staphylococcal scarlet fever. J Clin Microbiol 37:2446-2449

Johnson WM, Tyler SD, Ewan EP, Ashton FE, Pollard DR, Rozee KR (1991) Detection of genes for enterotoxins, exfoliative toxins, and toxic shock syndrome toxin 1 in Staphylococcus aureus by the polymerase chain reaction. J Clin Microbiol 29:426-430

Jones TF, Kellum ME, Porter SS, Bell M, Schaffner W (2002) An outbreak of community-acquired foodborne illness caused by methicillin-resistant Staphylococcus aureus. Emerg Infect Dis 8:82-84

Jørgensen HJ, Mørk T, Høgåsen HR, Rørvik LM (2005) Enterotoxigenic Staphylococcus aureus in bulk milk in Norway. J Appl Microbiol 99:158-166

Kluytmans J, van Leeuwen W, Goessens W, Hollis R, Messer S, Herwarld L, Bruining H, Heck M, Rost J, van Leeuwen N, van Belkum A, Verbrugh H (1995) Food-initiated outbreak of methicillin-resistant Staphylococcus aureus analyzed by pheno- and genotyping. J Clin Microbiol 33:1121-1128

Lyra DG, Sousa FGC, Borges MF, Givisiez PEN, Queiroga RCRE, Souza EL, Gebreyes WA, Oliveira CJB (2013) Enterotoxin-encoding genes in Staphylococcus spp. from bulk goat milk. Foodborne Pathog Dis 10:126-130

Malachowa N, DeLeo FR (2010) Mobile genetic elements of Staphylococcus aureus. Cell Mol Life Sci 67: 3057-3071

Manfreda G, Mioni R, De Cesare A (2005) Surveillance and characterization of enterotoxigenic staphylococci in foods of animal origin collected in the Veneto region. Vet Res Commun 29(S2):331-333

Monday SR, Bohach GA (1999) Use of multiplex PCR to detect classical and newly described pyrogenic toxin genes in staphylococcal isolates. J Clin Microbiol 37:3411-3414 
Morandi S, Brasca M, Lodi R, Cremonesi P, Castiglioni B (2007) Detection of classical enterotoxins and identification of enterotoxin genes in Staphylococcus aureus from milk and dairy products. Vet Microbiol 124:66-72

Mørk T, Bergsjø B, Sviland S, Kvitle B (2003) Humanpatogene bakterier i tankmelk fra ku og geit. National Veterinary Institute, Sluttrapport, Oslo

Murakami K, Minamide W, Wada K, Nakamura E, Teraoka H, Watanabe S (1991) Identification of methicillin-resistant strains of staphylococci by polymerase chain reaction. J Clin Microbiol 29:22402244

Normanno G, La Salandra G, Dambrosio A, Quaglia NC, Corrente M, Parisi A, Santagada G, Firinu A, Crisetti E, Celano GV (2007a) Occurrence, characterization and antimicrobial resistance of enterotoxigenic Staphylococcus aureus isolated from meat and dairy products. Int J Food Microbiol 115:290-296

Normanno G, Corrente M, La Salandra G, Dambrosio A, Quaglia NC, Parisi A, Greco G, Bellacicco AL, Virgilio S, Celano GV (2007b) Methicillin-resistant Staphylococcus aureus (MRSA) in foods of animal origin product in Italy. Int J Food Microbiol 117:219-222

Orden JA, Cid D, Blanco ME, Ruiz JA, Quiteria S, Gomez-Lucia E, de la Fuente R (1992) Enterotoxin and toxic shock syndrome toxin-one production by staphylococci isolated from mastitis in sheep. APMIS 100:132-134

Peles F, Wagner M, Varga L, Hein I, Rieck P, Gutser K, Keresztúri P, Kardos TI, Béri B, Szabó A (2007) Characterization of Staphylococcus aureus strains isolated from bovine milk in Hungary. Int J Food Microbiol 118:186-193

Pexara A, Solomakos N, Sergelidis D, Govaris A (2012) Fate of enterotoxigenic Staphylococcus aureus and staphylococcal enterotoxins in Feta and Galotyri cheeses. J Dairy Res 79:405-413

Pexara A, Solomakos N, Govaris A (2013) Prevalence of methicillin-resistant Staphylococcus aureus in milk and dairy products. J Hell Vet Med Soc 64:17-34

Poli A, Guglielmini E, Sembeni S, Spiazzi M, Dellaglio F, Rossi F, Torriani S (2007) Detection of Staphylococcus aureus and enterotoxin genotype diversity in Monte Veronese, a Protected Designation of Origin Italian cheese. Lett Appl Microbiol 45:529-534

Rola JG, Sosnowski M, Ostrowska M, Osek J (2015) Prevalence and antimicrobial resistance of coagulasepositive staphylococci isolated from raw goat milk. Small Rumin Res 123:124-128

Rosec JP, Gigaud O (2002) Staphylococcal enterotoxin genes of classical and new types detected by PCR in France. Int J Food Microbiol 77:61-70

Scherrer D, Corti S, Muehlherr JE, Zweifel C, Stephan R (2004) Phenotypic and genotypic characteristics of Staphylococcus aureus isolates from raw bulk-tank milk samples of goats and sheep. Vet Microbiol 101:101-107

Schønberg KC, Wåltorp M (2001) Staphylococcal food poisoning after consumption of goat cheese made from raw milk. In MSIS-rapport 47 2001. Oslo: Norwegian Institute of Public Health

Spanu V, Scarano C, Virdis S, Melito S, Spanu C, De Santis EPL (2013) Population structure of Staphylococcus aureus isolated from bulk tank goat's milk. Foodborne Pathog Dis 10:310-315

Tsen H-Y, Chen T-R (1992) Use of the polymerase chain reaction for specific detection of type A, D and E enterotoxigenic Staphylococcus aureus in foods. Appl Microbiol Biotechnol 37:685-690

Valle J, Gomez-Lucia E, Piriz S, Goyache J, Orden JA, Vadillo S (1990) Enterotoxin production by staphylococci isolated from healthy goats. Appl Environ Microbiol 56:1323-1326

Vyletělova M, Hanuš O, Karpiškova R, Št’astkova Z (2011) Occurrence and antimicrobial sensitivity in staphylococci isolated from goat, sheep and cow milk. Acta Univ Agriculturae et Silviculturae Mendeleianae Brunensis 59(3):209-213

Zouharova M, Rysanek D (2008) Multiplex PCR and RPLA identification of Staphylococcus aureus enterotoxigenic strains from bulk tank milk. Zoonoses Public Health 55:313-319 